\title{
Circulating Agonist Autoantibody to 5-Hydroxytryptamine 2A Receptor in Lean and Diabetic Fatty Zucker Rat Strains
}

\author{
Zimering $\mathrm{MB}^{1,2 *}$, Grinberg $\mathrm{M}^{1}$, Burton $\mathrm{J}^{1}$ and Pang $\mathrm{KCH}^{1,3}$ \\ ${ }^{1}$ Medical Service, Veterans Affairs New Jersey Healthcare System, East Orange, New Jersey, USA \\ ${ }^{2}$ Rutgers-Robert Wood Johnson Medical School, New Brunswick, NJ; 3 Rutgers-New Jersey Medical School, Newark, New Jersey, USA
}

${ }^{\star}$ Corresponding author: Mark B. Zimering, Medical Service, Veterans Affairs New Jersey Healthcare System, East Orange, New Jersey, USA; Email: mark.zimering@va.gov Received: July 23, 2020; Accepted: July 28, 2020; Published: August 28, 2020

\begin{abstract}
Aims: Circulating neurotoxic autoantibodies to the 5-hydroxytryptamine 2A receptor were increased in older adult type 2 diabetes in association with certain neurodegenerative complications. The male Zucker diabetic fatty (ZDF) rat is a model system for studies of obese, type 2 diabetes mellitus. The aim of the current study was to test for (and compare) circulating neurotoxic autoantibodies to the 5-hydroxytryptamine $2 \mathrm{~A}$ receptor in the Zucker diabetic fatty rat and age-matched lean Zucker rat strains.
\end{abstract}

Methods: Plasma from lean and Zucker diabetic fatty rat (obtained at different developmental stages) was subjected to protein G affinity chromatography. The resulting immunoglobulin $\mathrm{G}$ fraction was tested for neurotoxicity (acute neurite retraction, accelerated neuron loss) in N2A mouse neuroblastoma cells and for binding to a linear synthetic peptide corresponding to the second extracellular loop of the 5-hydroxytryptamine $2 \mathrm{~A}$ receptor.

Results: The male Zucker diabetic fatty rat ( $f a / f a)$ and two Zucker lean strains (+/?) and (fa/+) harbored autoantibodies to the 5-hydroxytryptamine 2A receptor which appeared spontaneously around 7-8.5 weeks of age. The circulating autoantibodies persisted until at least 25 weeks of age in the Zucker diabetic fatty rat and in the Zucker heterozygote ( $f a /+)$, but were no longer detectable in 25-week-old lean (+/?) Zucker rats. Autoantibodyinduced acute neurite retraction and accelerated loss in mouse neuroblastoma N2A cells was dose-dependently prevented by selective antagonists of the 5-hydroxytryptamine $2 \mathrm{~A}$ receptor. It was also substantially prevented by co-incubation with antagonists of RhoA/Rho kinase-mediated signaling (Y27632) or Gq11/phospholipase C/inositol triphosphate receptor-coupled signaling.

Conclusions: These data suggest that neurotoxic 5-hydroxytryptamine 2A receptor-targeting autoantibodies increase in the aging male Zucker diabetic fatty rat and in male Zucker lean rats harboring a heterozygous mutation, but not in age-matched, older Zucker lean rats lacking a known leptin receptor mutation. The Zucker genetic strain may be useful in studies of the role of humoral and/or innate immunity in late neurodegeneration.

\section{Introduction}

Type 2 diabetes mellitus is associated with an increased risk of late neurodegeneration $[1,2]$ via mechanisms which may involve (in part) increased peripheral and central inflammation. Increased proinflammatory cytokines and innate immunity have been associated with early Parkinson's disease [3] and dementia [4] through complex mechanisms. Leptin is a hormone released by fat cells that is important in energy metabolism. Dysfunction of the leptin system results in classic signs of type 2 diabetes mellitus, such as obesity, insulin resistance and high circulating insulin. Leptin is also a member of the type 1 cytokine family that includes interleukin- $6[5,6]$. The leptin receptor is normally expressed on hematopoietic cells where it stimulates helper-T cell, and effector $\mathrm{T}$ cell functions and inhibits regulatory $\mathrm{T}$ cell function [7].

The male Zucker Diabetic Fatty rat $(f a / f a)$ (ZDF) is a wellrecognized animal model of obese type 2 diabetes mellitus and hypertension [8,9] in which hyperphagia causes morbid obesity leading to high level of pro-inflammatory adipocytokines [10]. In the ZDF rat, pro-inflammatory cytokines cause enhanced innate immunity [11], however, owing to its complete leptin receptor deficiency, helper T-cell function is reduced [12]. The lean heterozygous Zucker rat $(f a /+)$ has haplo-sufficiency at the leptin receptor and a twofold increased plasma leptin concentration [13] compared to the wild-type $(+/+)$ lean Zucker rat. Since hyperleptinemia promoted helper-T cell-mediated autoantibody formation and worsened clinical outcome(s) in a mouse model of systemic lupus erythematosus [14], the lean heterozygote Zucker rat might be expected to exhibit higher autoantibody expression than in the $\operatorname{ZDF}(f a / f a)$ rat strain.

In prior studies in older adult (human) obese type 2 diabetes, patients harboring increased circulating autoantibodies to the 5-hydroxytryptamine $2 \mathrm{~A}$ receptor (5-HT2AR) had an increased prevalence of co-morbid neurodegenerative complications including Parkinson's disease and dementia [15]. Human plasma autoantibodies targeting the 5-HT2A receptor promoted long-lasting (agonistic) activation of $\mathrm{Gq11/phospholipase} \mathrm{C/inositol} \mathrm{triphosphate} \mathrm{receptor/}$ 
$\mathrm{Ca} 2+$ signaling causing accelerated endothelial cell and neuronal cell death [16]. Since the 5-hydroxytryptamine $2 \mathrm{~A}$ receptor is normally expressed on arterial smooth muscle cells [17] and on neurons in specific brain regions involved in the regulation of mood, thinking, perception, and sleep [18], altered signaling at the 5-HT2A receptor could have diverse peripheral and central effects.

The aim of the present study was to test for spontaneouslyoccurring autoantibodies to the 5-HT2A receptor in the circulation in male ZDF rat $(f a / f a)$ and age-matched male lean Zucker rats either lacking a known leptin receptor mutation $(+/$ ?) or harboring a heterozygous leptin receptor mutation $(f a /+)$. The developmental expression of autoantibody was compared in each genetic strain, and the mechanism of neurotoxicity downstream of 5-HT2AR binding was evaluated in mouse neuroblastoma N2A cells.

\section{Materials and Methods}

\section{Animals}

All procedures were conducted according to the National Institutes of Health (NIH) Guide for the Care and Use of Laboratory Animals and approved by the Institutional Animal Care and Use Committee of the Veterans Affairs Medical Center (East Orange, New Jersey). Male ZDF $(\mathrm{N}=12)$ and lean $(+/$ ? $)$ Zucker rats $(\mathrm{N}=12)$ were obtained from Charles River Laboratories (Kingston, NY) at approximately 6 weeks of age. All rats were single housed upon arrival, with modest enrichment (a PVC tube). Rats were provided ad libitum access to food and water and maintained in a $12 \mathrm{~h}$ light/dark cycle with lights on at 0630 . All procedures occurred during the light phase of the cycle.

\section{Blood Drawing}

EDTA plasma from 10-week ZDF rat and 10-week lean, heterozygous $(f a /+)$ Zucker rats was obtained from Charles River Laboratories. For all other time points, blood was collected from the retro-orbital plexus of ZDF, and lean (+/?) Zucker rats using a retroorbital blood procedure. The blood was centrifuged at $1400 \mathrm{~g} \mathrm{x} 10$ minutes at 4 degrees $\mathrm{C}$. The resulting plasma was stored at $-4^{\circ} \mathrm{C}$ for up to 2-3 weeks prior to protein $\mathrm{G}$ affinity chromatography.

\section{Tail-Nick}

Capillary blood glucose was determined from a drop of blood obtained after tail nick at sequential time intervals. A glucose dehydrogenase method (Accucheck Aviva, Roche Diagnostics, Inc) was used for the determination of blood glucose.

\section{Protein G Affinity Chromatography}

Protein-G affinity chromatography was carried out as previously reported for protein-A affinity chromatography in human plasma [16]. The $\mathrm{pH}$ of the $10 \mathrm{~mm}$ Tris binding buffer (6.5) and the $0.1 \mathrm{M}$ citrate elution buffer (2.7) was adjusted to optimize binding and elution of rat immunoglobulin G. Protein-G eluate fractions were stored at 0-4 degrees $\mathrm{C}$.

\section{Mouse N2A Neuroblastoma Cells}

Cells were cultured in DMEM with $10 \%$ fetal calf serum as previously reported [16].

\section{Neurite Retraction and N2A Cell Survival Assays}

Assays were performed as previously described [16].

\section{Enzyme-Linked Immunoassay (ELISA)}

The ELISA procedure was carried out as previously reported using an 18-meric linear synthetic peptide Q..N18 corresponding to the second extracellular loop of the human 5-HT2AR as the solid phase antigen [15].

\section{Chemicals}

All chemicals were obtained from Sigma Co., Inc. (St. Louis, MO).

Protein determination-Protein levels were determined using a bichinchonic assay method (BioRad, Inc.).

\section{Statistics}

Statistical analysis was performed using an unpaired Student's t-test with an $\alpha$ cutoff level for significance of $<0.05$.

\section{Results}

\section{Occurrence of Circulating 5-HT2A Receptor Autoantibody in the ZDF Rat: Relation to Obesity and Diabetes}

Mean body mass in ZDF rats significantly exceeded that in lean $(+/$ ?) Zucker rat at week 7, week 8.5, and week 12 (Figure 1A). There

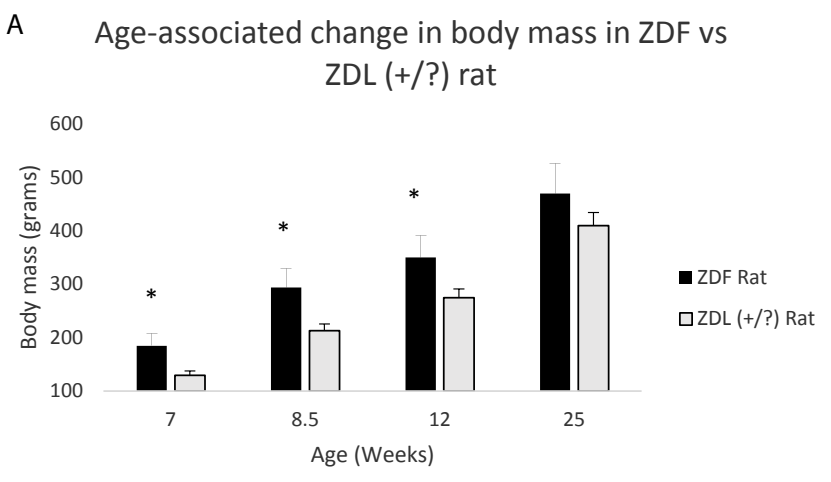

B

Age-associated change in capillary blood glucose in ZDF vs. ZDL male rat

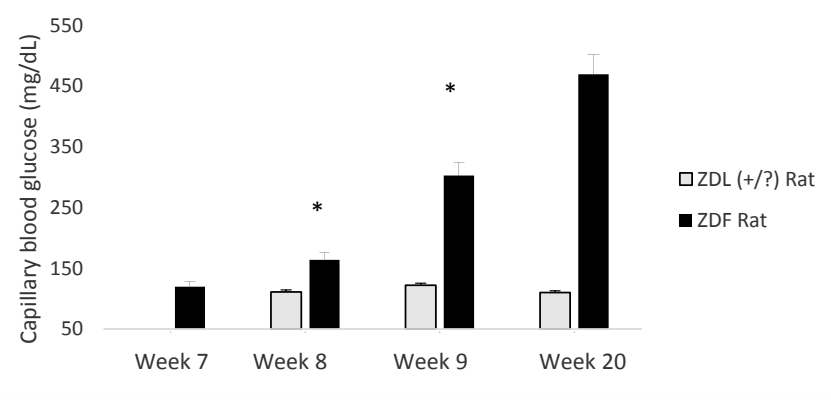

Figure 1: Age-dependent change in body mass (A) and capillary blood glucose concentration (B) in male Zucker fatty (ZDF) vs lean (+/?) (ZDL) rats. A) Body weight increased significantly in the male ZDF rat (starting at week 7) compared to control lean Zucker rat B) capillary blood glucose was determined by tail nick using glucose dehydrogenase method as described in Materials and Methods. Glucose was normal at week 7 in the ZDF rat, but increased significantly compared to ZDL rat starting at week 8 . 
was no longer a significant weight difference between the strains at week 25 (Figure 1A). Diabetes (hyperglycemia) emerged between week 8-10 in the ZDF rat, but at week 7 the ZDF rat was still normoglycemic (Figure 1B). In contrast, lean (+/?) Zucker rats were normoglycemic at all ages tested (Figure 1B), not tested at week 7.

Detection of plasma immunoreactive 5-HT2AR autoantibody had a similar trajectory to diabetes in ZDF rats. At 7 weeks of age, ZDF rat had no detectable plasma immunoreactive 5-HT2AR autoantibody (Figure 1C). At 10-weeks of age, plasma from ZDF rat contained a two-fold, higher binding to 5-HT2AR (0.14 AU, N=2) compared to background levels (0.07 AU; Figure 2A). Plasma from lean $((+/$ ? $)$ Zucker rats harbored two-fold or slightly higher level of autoantibody binding to 5-HT2AR between 8.5-15 weeks of age which declined to undetectable levels at 25 weeks of age (Figure 2B).

Spontaneous IgG autoantibody to the 5-HT2A receptor was ZDF (faffa)

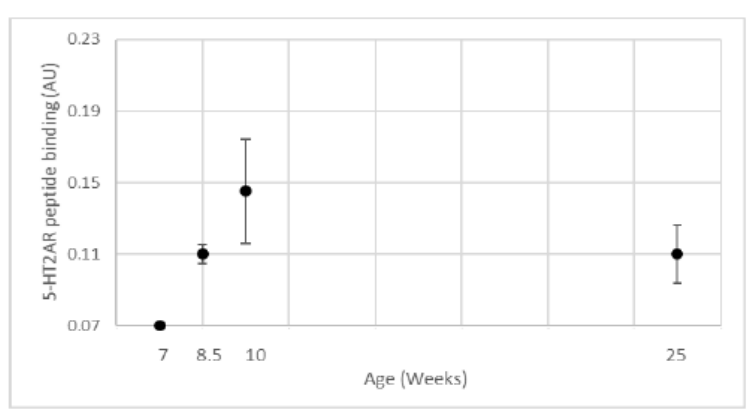

ZDL $(+/ ?)$

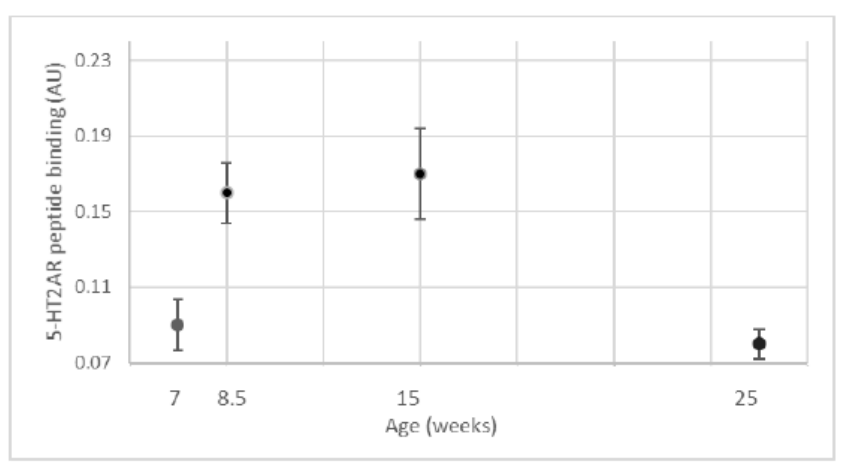

$(f a /+)$

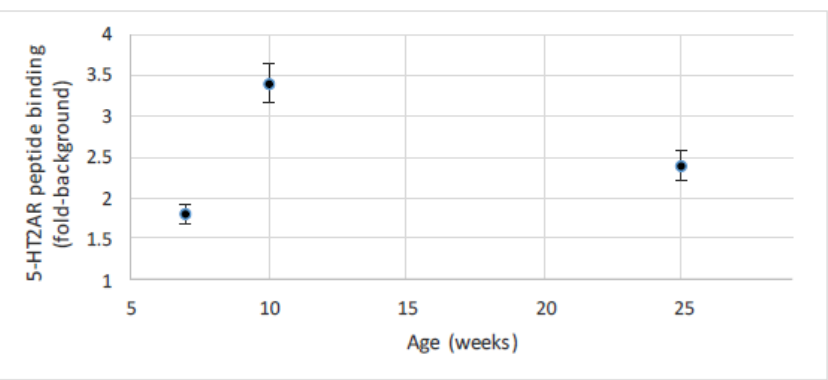

Figure 2: Developmental expression of autoantibody binding to 5-HT2AR synthetic peptide in three Zucker rat strains. A $2 \mathrm{ug} / \mathrm{mL}$ concentration of the protein $\mathrm{G}$ eluate was tested for binding to the linear synthetic 18-meric 5-HT2A receptor peptide as described in Materials and Methods. Results are "mean +/- SE" in A) ZDF rat: 7-week (N=2); 8.5week $(\mathrm{N}=3)$; 10-week $(\mathrm{N}=2) ; 25$-week $(\mathrm{N}=3)$ B) lean $(+/$ ?) Zucker rat: 7-week $(\mathrm{N}=3) ; 8.5$ week $(\mathrm{N}=3)$; 15 -week $(\mathrm{N}=10) ; 25$-week $(\mathrm{N}=6)$. C) lean heterozygote $(\mathrm{fa} /+)$ Zucker rat: 7-week (N=2); 10-week (N=5); 25-week (N=2). already present at 7 weeks of age in the heterozygous lean $(\mathrm{fa} /+)$ Zucker rat (Figure 2C) and levels at 10-weeks old and 25-weeks old were substantially higher than in age-matched ZDF rat (Figure 2C). Autoantibody to the 5-HT2A receptor persisted into older age, i.e. 25 weeks old, in male ZDF and lean heterozygous Zucker rats, but disappeared at 25 weeks of age in the lean (+/?) Zucker rat lacking a known leptin receptor mutation. In a recent report [19], diabetes, obesity and hypertension were associated with substantially increased hazard rates for the occurrence of dementia, Parkinson's disease and severe depression following traumatic brain injury in older adult veterans.

The present data suggest that male ZDF and heterozygous lean rat strains may be useful in modeling the effects of heightened innate and/or adaptive immunity, respectively, on the occurrence of neurodegeneration.

\section{Zucker Diabetic Fatty Rat Plasma 5-HT2AR Autoantibody Inhibits N2A Cell Survival}

We next tested for neurotoxicity in the autoantibody (from 10-week-old ZDF rat plasma) that displayed increased binding to the 5-HT2A receptor peptide. Autoantibody in plasma from the 10 -week old ZDF rat caused dose-dependent inhibition of survival in N2A mouse neuroblastoma cells (Figure 3). A two and one-half microgram per milliliter concentration of the IgG caused approximately $40 \%$ neuroblastoma cell loss (after 24 hours incubation) compared to control, untreated cells $(\mathrm{P}<0.01$, Figure 3$)$.

\section{Zucker Diabetic Fatty Rat Plasma 5-HT2AR Autoantibody Causes Acute N2A Neurite Retraction}

A 120 nanomolar concentration $(1.8 \mu \mathrm{g} / \mathrm{mL} \operatorname{IgG})$ of the protein G-eluate fraction of plasma from 10-week-old male ZDF fatty rat caused significant $37 \%$ acute neurite length-shortening (after 15 minutes of incubation) of N2A mouse neuroblastoma cells (Figure 4A). Co-incubation with a 200 nanomolar concentration of M100907, a highly selective, potent antagonist of the 5-HT2AR, afforded $86 \%$ significant $(\mathrm{P}<0.01)$ protection against autoantibody-induced neurite retraction (Figure $4 \mathrm{~A})$.

\section{Dose-dependent neurotoxicity in autoantibodies from} Zucker Diabetic Fatty Rat Plasma

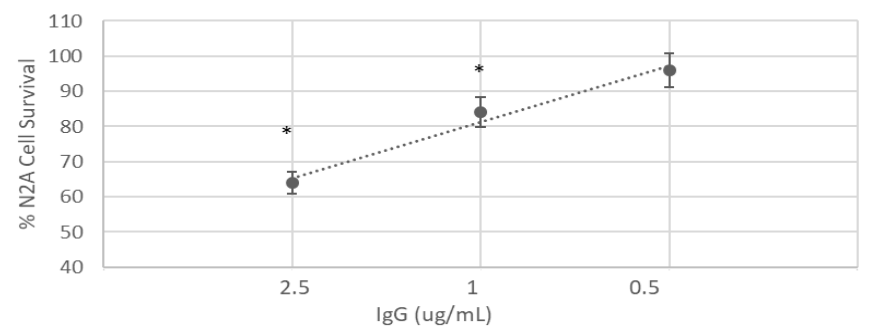

Figure 3: Dose-dependent neurotoxicity in the protein $G$ eluate fraction from Zucker diabetes fatty rat plasma. The protein G-eluate fraction from 10-week-old male Zucker diabetic fatty rat plasma was incubated with N2a mouse neuroblastoma cells (at the indicated concentrations) for 24 hours. \% N2a cell survival was determined with an MTT assay as described in Materials and Methods. Each point represents the mean $+\mathrm{SE}$ of quadruplicate determinations; ${ }^{*} \mathrm{P}<0.01$ compared to cell survival in untreated cells. 


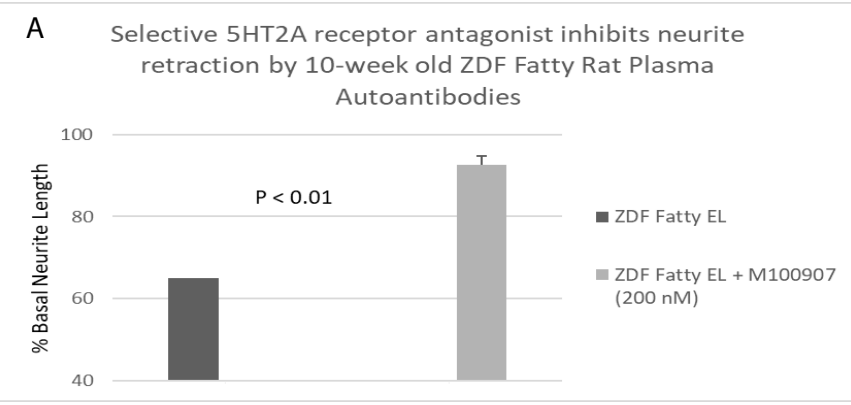

B Neutralization of ZDF Rat IgG Neurotoxicity by 5-HT2A Receptor Antagonists

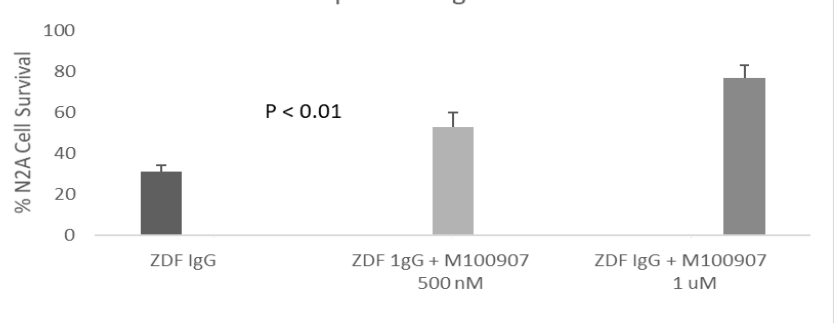

Figure 4: Neurite outgrowth inhibition (A) and accelerated N2A neuroblastoma cell loss (B) in autoantibody from ZDF rat plasma: neutralization by M100907, a highly selective 5-HT2AR antagonist. A) A $120 \mathrm{nM}$ concentration of the protein-G eluate fraction of 10-week-old male ZDF rat plasma was incubated with N2A mouse neuroblastoma cells in the presence or absence of a $200 \mathrm{nM}$ concentration of the selective 5-HT2AR antagonist M100907. \% Basal neurite length was determined after 15 minutes as described in Materials and Methods B) A $160 \mathrm{nM}$ concentration of the protein G-eluate fraction from 10-week-old male Zucker diabetic fatty rat plasma was incubated with N2a mouse neuroblastoma cells in the presence or absence of the indicated concentration of M100907 for 24 hours at $37 \mathrm{deg}$ C. Percent N2A cell survival was determined with an MTT assay as described in Materials and Methods. Each point represents the mean + SE of triplicate determinations.

\section{Pharmacologic Profile of Zucker Diabetic Fatty Rat Plasma 5-HT2AR Autoantibody Toxicity}

A $~ 170$ nanomolar concentration $(2.5 \mu \mathrm{g} / \mathrm{mL})$ of the protein G-eluate fraction of plasma from 10 -week-old male ZDF rat was incubated with $\mathrm{N} 2 \mathrm{~A}$ mouse neuroblastoma cells in the presence or absence of a (500 or 1000) nanomolar concentration of M100907 for 24 hours at $37 \mathrm{deg}$ C. M100907 caused significant (dose-dependent) protection against accelerated N2A cell loss, after 24 hours incubation with the ZDF rat IgG (Figure 4B).

Spiperone is a potent, but less selective 5-HT2AR antagonist. Spiperone at 500-1000 nanomolar concentrations afforded significant dose-dependent protection against ZDF rat IgG-induced accelerated N2A cell loss (Figure 5). Ketanserin is a less potent 5-HT2AR antagonist compared to M100907 or spiperone. Substantially higher concentration $(2.5 \mu \mathrm{M})$ of ketanserin was required to significantly protect against ZDF rat IgG-induced N2A cell loss (Figure 6).

The receptor antagonist profile and concentration associated with significant protection against ZDF IgG autoantibody-induced neuroblastoma cell loss is consistent with relative affinity constants on the 5-HT2A receptor (M100907 < spiperone $<<$ ketanserin).

A one micromolar concentrations of SB-20471, a selective antagonist to the 5-HT2B receptor did not significantly prevent ZDF autoantibody-induced neurite retraction (Table 1). A ten micromolar

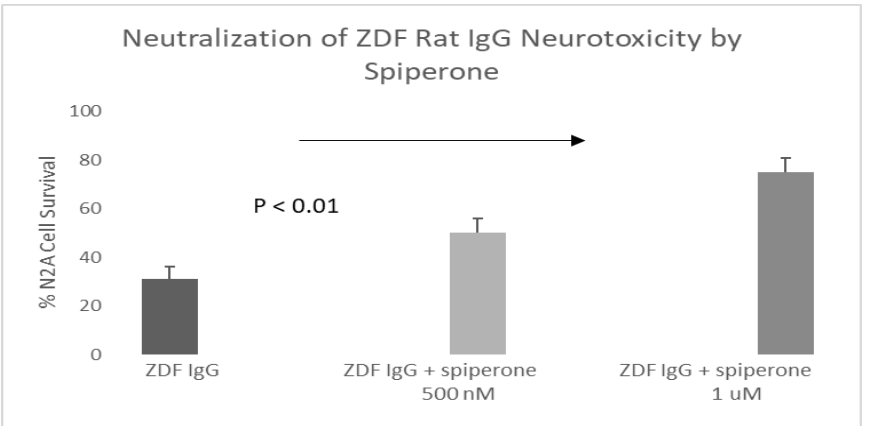

Figure 5: Potent, less selective 5-HT2AR antagonist (spiperone) dose-dependently prevented accelerated neuron loss induced by ZDF rat plasma autoantibody. A $160 \mathrm{nM}$ concentration of the protein G-eluate fraction from 10-week-old male Zucker diabetic fatty rat plasma was incubated with N2a mouse neuroblastoma cells in the presence or absence of the indicated concentration of spiperone for 24 hours at 37 deg C. Percent N2a cell survival was determined with an MTT assay as described in Materials and Methods. Each point represents the mean $+\mathrm{SE}$ of triplicate determinations.

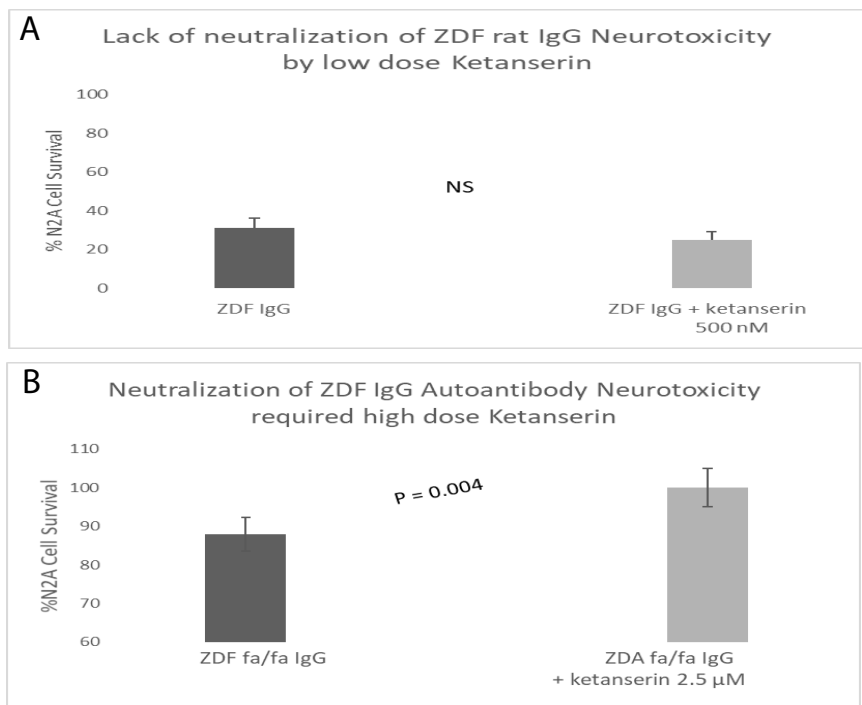

Figure 6: Higher concentration of ketanserin, a less potent, but selective 5-HT2AR antagonist dose-dependently prevented accelerated neuron loss induced by ZDF rat plasma autoantibody A-B) $120 \mathrm{nM}$ concentration of the protein G-eluate fraction from 10-weekold male Zucker diabetic fatty rat plasma was incubated with N2a mouse neuroblastoma cells in the presence or absence of the indicated concentration of ketanserin for 24 hours at 37 deg C. Percent N2a cell survival was determined with an MTT assay as described in Materials and Methods. Each point represents the mean + SE of triplicate determinations.

Table 1: Receptor specificity of prevention of ZDF rat IgG autoantibody-induced acute $\mathrm{N} 2 \mathrm{~A}$ neurite retraction.

\begin{tabular}{|c|c|c|c|}
\hline Antagonist & Conc & GPCR & \% of ZDF IgG-induced Neurite Retraction \\
\hline M100907 & $200 \mathrm{nM}$ & 5HT2A & $13 \% \pm 15 \%$ \\
\hline SB-20471 & $1 \mu \mathrm{M}$ & 5HT2B & $89 \% \pm 20 \%$ \\
\hline Bosentan & $10 \mu \mathrm{M}$ & ET-1 & $95 \% \pm 20 \%$ \\
\hline Losartan & $10 \mu \mathrm{M}$ & AT-1 & $81 \% \pm 5 \%$ \\
\hline Prazosin & $850 \mathrm{nM}$ & A1-A & $89 \% \pm 11 \%$ \\
\hline
\end{tabular}

A 160 nanomolar concentration of 10-week-old male Zucker fatty rat IgG autoantibodies was incubated in the presence or absence of the indicated GPCRs. Acute N2A neurite retraction was determined after 15 minutes as described in Materials and Methods. Results are mean \pm SD.

concentration of either bosentan (an endothelin-1 receptor) or losartan (an angiotensin II type 1 receptor) antagonist did not significantly protect against ZDF IgG-induced acute N2A neurite retraction (Table 1). An 850 nanomolar concentration of prazosin (alpha 1 adrenergic 
$\mathrm{R}$ antagonist) did not afford significant protection against ZDF IgG autoantibody-induced acute neurite retraction (Table 1). Taken together, these data suggest that neurotoxicity in the 10-week old male ZDF rat IgG appears selective for the 5-HT2A receptor.

\section{Involvement of Gq11/Phospholipase C/Inositol Triphosphate and Rho Kinase Signaling Pathways}

Co-incubation of N2A cells with ZDF plasma IgG autoantibodies together with individual selective antagonists of Gq11 (YM-254890), phospholipase C (U73122), inositol triphosphate receptor (2-APB) signaling or Rho A/Rho kinase (Y27632) mediated signaling completely or nearly completely protected against acute neurite retraction (Table 2) consistent with involvement of Gq11/phospholipase C/inositol triphosphate and Rho kinase signaling pathways in mediating $\operatorname{IgG}$ neurotoxicity downstream of 5-HT2A receptor binding.

Table 2: Effect of signaling pathway inhibitors on ZDF rat IgG autoantibody-induced acute $\mathrm{N} 2 \mathrm{~A}$ neurite retraction.

\begin{tabular}{|c|c|c|c|}
\hline Antagonist & Conc & Signaling Intermediate & $\begin{array}{c}\text { \% of ZDF IgG-induced Neurite } \\
\text { Retraction }\end{array}$ \\
\hline U73122 & $10 \mu \mathrm{M}$ & PLC & $14 \% \pm 13 \%$ \\
\hline YM-254890 & $1 \mu \mathrm{M}$ & Gq11 & $14 \% \pm 5 \%$ \\
\hline $2-A P B$ & $50 \mu \mathrm{M}$ & IP3R & $0 \% \pm 0 \%$ \\
\hline Y27632 & $10 \mu \mathrm{M}$ & Rho kinase & $0 \% \pm 0 \%$ \\
\hline
\end{tabular}

A 160 nanomolar concentration of 10 -week-old male Zucker fatty rat IgG autoantibodies was incubated in the presence or absence of the indicated GPCRs. Acute N2A neurite retraction was determined after 15 minutes as described in Materials and Methods. Results are mean \pm SD as described in Materials and Methods.
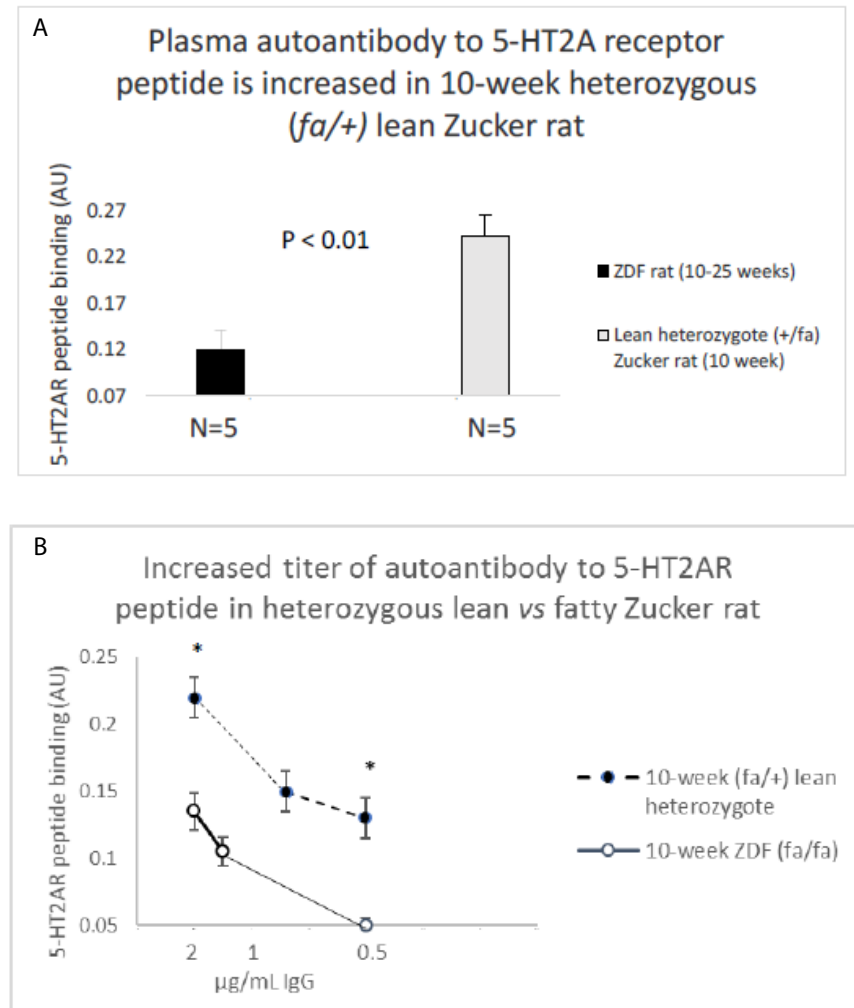

Figure 7: A) $2 \mathrm{ug} / \mathrm{mL}$ concentration of the protein G eluate of ZDF rat and lean Zucker heterozygote plasma was tested for binding to linear, synthetic 18-meric 5-HT2A receptor peptide. B) Titer of autoantibody binding to 5-HT2A receptor peptide was tested at the indicated concentrations in 10-week lean Zucker heterozygote $(\mathrm{N}=5)$ or 10-week ZDF $(\mathrm{N}=2)$ protein $\mathrm{G}$ eluate. Results are "mean $+/-\mathrm{SE}$ ” ${ }^{\star} \mathrm{P}<0.01$

\section{Level and Titer of Autoantibody to 5-HT2A Receptor in Male Zucker Heterozygote $(\mathrm{fa} /+)$}

An identical ( $1.5 \mu \mathrm{g} / \mathrm{mL}$ concentration) of the IgG from Zucker heterozygote rat plasma $(\mathrm{N}=5)$ displayed two-fold significantly higher binding (to the 5-HT2A receptor peptide) compared to IgG in plasma from five $\mathrm{ZDF}$ rat plasmas $(\mathrm{N}=2,10$-week-old and $\mathrm{N}=3,25$-week-old rats) (Figure 7A). The titer of autoantibody to the 5-HT2A receptor peptide was more than two-fold higher in the 10-week old lean Zucker heterozygous rat compared to age-matched, 10 -week old ZDF rat (Figure 7B).

\section{Bioactivity in the Antibody Fraction of Male Zucker Heterozygous (fa/+) Plasma}

Dose-dilution curves of the protein-G eluate fraction from three, 10-week-old lean heterozygous Zucker heterozygous plasmas demonstrated potent inhibition of $\mathrm{N} 2 \mathrm{~A}$ cell survival at all $\mathrm{IgG}$ concentrations tested in two of three rats (Figure 8A). In one of the three rats, lean heterozygous Zucker rat \#3, a component of significant N2A survival-promoting activity were observed at high IgG dilution (Figure 8A). 'Functional selectivity' is a unique property of the 5-hydroxytryptamine $2 \mathrm{~A}$ receptor [20]-it refers to the ability of different 5-HT2AR ligands to preferentially activate alternative signaling pathways, e.g. PLC/IP3/Ca2+ signaling or a beta-arrestin 2/ PI3-kinase survival pathway. Since the selective 5-HT2AR antagonist M100907 significantly protected against lean heterozygous Zucker

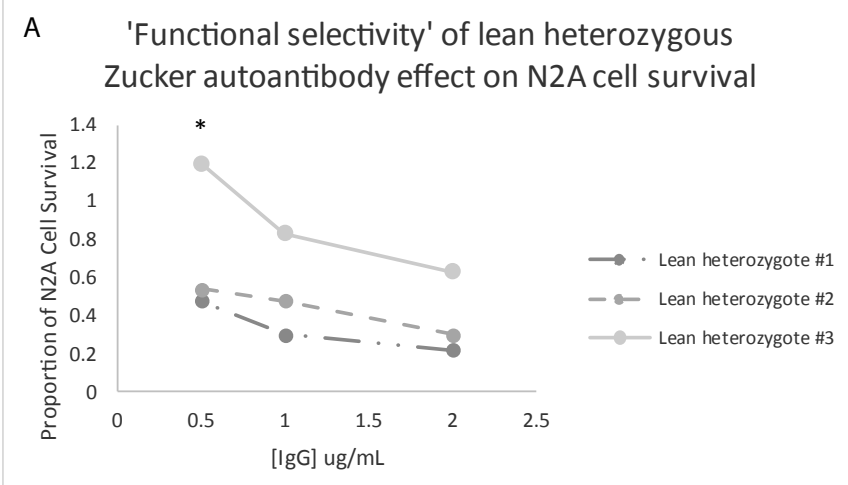

B M100907 neutralizes neurotoxicity in lean, heterozygote Zucker rat protein $\mathrm{G}$ eluate

60

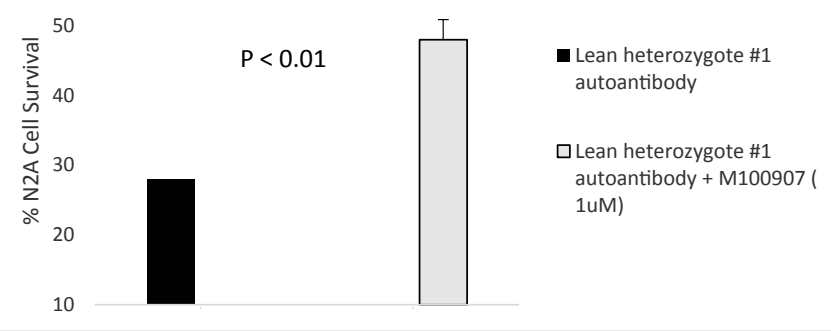

Figure 8: A) Dose-dilution curves of three Zucker lean heterozygous protein G eluates on survival in N2A mouse neuroblastoma cells; B) Co-incubation of a representative lean heterozygous protein $\mathrm{G}$ eluate fraction with $1 \mu \mathrm{M}$ concentration of the selective 5-HT2AR antagonist M100907. ${ }^{*} \mathrm{P}<0.05$. 
rat IgG autoantibody-induced accelerated N2A cell loss (Figure 8B) the neurotoxicity is likely due to Gq11/PLC/IP3/Ca2+-mediated signaling occurring downstream of 5-HT2AR binding. More study is needed, however, to determine whether N2A survival-promoting activity in a subset of lean heterozygous Zucker rat IgG autoantibodies may result from selective activation of beta arrestin-2/PI3-kinasemediated signaling. In a prior report [21], highest level of 5-HT2A receptor-binding occurring in the autoantibodies from a patient with lupus. The lupus IgG autoantibodies were not only neurotoxic, but (at certain concentrations) promoted N2A neuroblastoma cell survival dependent on PI3 kinase-mediated signaling [21].

\section{Apparent MW of the Active Component in ZDF Protein G Eluates}

The active component in the ZDF protein G eluate (which caused accelerated N2A cell loss) had an apparent MW > $10 \mathrm{kD}$ (Figure 9A) consistent with an antibody or antibody fragment. There was no significant N2A cell survival-inhibitory activity present in the flowthrough fraction following membrane dialysis of the ZDF protein $G$ eluate on a 10 kilodalton Molecular Weight (MW) cutoff membrane (Figure 9A). The freshly-isolated, lean heterozygous Zucker rat (fa/+) protein $\mathrm{G}$ eluate fraction (SM, starting material) caused significantly increased N2A cell survival. Following dialysis on a $10 \mathrm{kD}$ MW cutoff membrane, more than $90 \%$ of the N2A survival stimulatory activity was recovered in the fraction having an apparent $\mathrm{MW}>10 \mathrm{kD}$, i.e.

\section{A} Dialysis of ZDF Plasma Protein G Eluate on 10 kD MW Cutoff Membrane
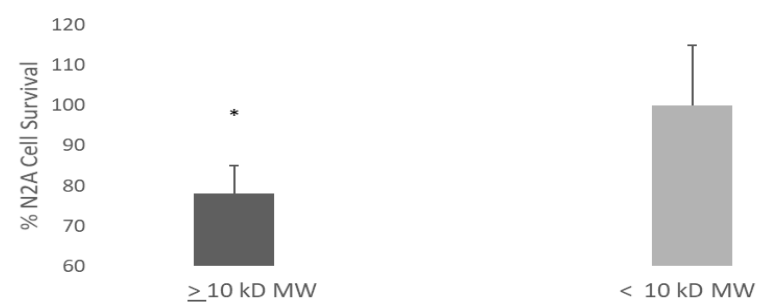

B

Dialysis of Lean Heterozygote \#3 Plasma Protein G Eluate on

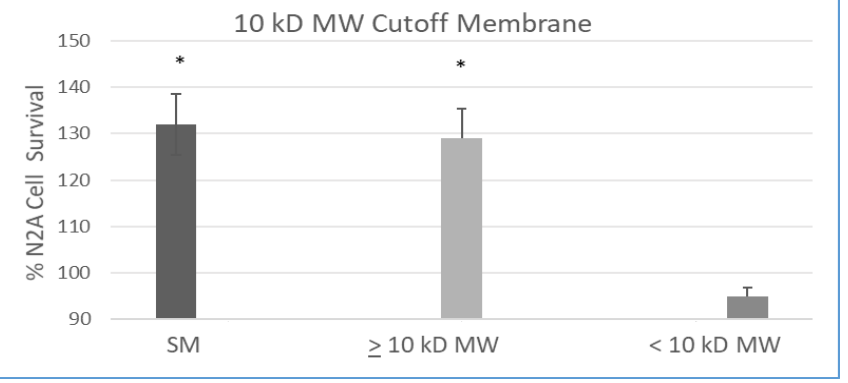

Figure 9: Apparent MW of peak neuroblastoma survival-inhibitory (A) and -stimulatory (B) activity in the plasma protein G eluate from ZDF or heterozygous lean ZDL rat. Apparent MW of peak neuroblastoma survival-inhibitory (A) or -stimulatory (B) activity in the protein $\mathrm{G}$ eluate from a representative $\mathrm{ZDF}(\mathrm{A})$ and lean heterozygote \# 3 Zucker rat (B) plasma. A $160 \mathrm{nM}$ concentration of the protein G-eluate fraction from 10-weekold male Zucker rat plasma was dialyzed on a $10 \mathrm{kD}$ MW cutoff membrane. The resulting retained and flow-through fractions or starting material (SM) were incubated with N2a mouse neuroblastoma cells for 24 hours as described in Materials and Methods. Each point represents the mean $+\mathrm{SE}$ of triplicate determinations. ${ }^{*} \mathrm{P}<0.05$ compared to control $\mathrm{N} 2 \mathrm{~A}$ cell without added test fractions. retained on the membrane (Figure 9B). The low MW ( $<10 \mathrm{kD})$ flowthrough fractions following membrane dialysis of the ZDF or lean heterozygous Zucker rat protein $\mathrm{G}$ eluate did not cause significant inhibition or stimulation of N2A survival (Figure 9A and 9B).

\section{Discussion}

The male ZDF rat is a well-studied model of human obese type 2 diabetes mellitus. The animals undergo progressive gain in fat mass, with obesity arising around 4-weeks of age [9]. Hyperglycemia commences around week 8-9, and chronic marked elevation in blood glucose concentrations $(400-500 \mathrm{mg} / \mathrm{dL})$ is associated with early hyperinsulinemia followed by later relative insulin deficiency [10]. Hypertension and severe hypertriglyceridemia manifest around week 9 in the ZDF rat $[9,10]$. In adult, long-standing human obese type 2 diabetes mellitus from the Veterans Affairs Diabetes Trial, the baseline presence of anti-endothelial cell autoantibodies was significantly associated with lack of baseline insulin therapy (i.e. relative insulin deficiency) and lack of baseline triglyceride-lowering medication [22]. Endothelial cell heparanase expression is upregulated in insulin deficiency [23] and by high level of pro-inflammatory cytokines [24]. Heparanase cleaves heparan sulfate side chains abundant on neurons and vascular cells, and heparan sulfate proteoglycan is a known target of humoral autoimmunity [25]. In older adult diabetes patients evidence suggested that autoantibodies targeting the 5-HT2AR were in many cases cross-reactive with heparan sulfate proteoglycan [26]. Taken together it is possible that certain metabolic derangements in the ZDF rat strain, (insulin deficiency, and high level of pro-inflammatory cytokines) may contribute in part to the long persistence of circulating 5-HT2A receptor autoantibodies at older ages.

Although the heterozygous $(\mathrm{fa} /+)$ Zucker rat is lean and nondiabetic, it demonstrated substantially higher titer of 5-HT2A receptor autoantibodies compared to age-matched ZDF rat. One possibility is that enhanced helper T-cell immunity in the lean heterozygote Zucker rat drives autoantibody formation which includes a subset (of autoantibodies) targeting the 5-HT2A receptor. Neurotoxicity in the lean heterozygote Zucker IgG autoantibodies (i.e. acute neurite retraction and accelerated N2A cell loss) was as high or higher than in ZDF IgG autoantibodies consistent with a prior report of a significant correlation between antibody binding level and level of acute neurite retraction in N2A cells [15]. Higher level of 5-HT2AR targeting autoantibodies in the lean heterozygote Zucker rat supports a role for upregulated adaptive humoral immunity (in part) due to a heterozygous leptin receptor mutation causing hyperleptinemia. More study is needed to determine whether high titer of autoantibodies in the lean heterozygous Zucker rat may predispose to immune complex formation that could bias signaling pathway activation downstream of 5-HT2A receptor binding.

In summary, 5-HT2A receptor autoantibodies increased in the circulation in male hypertensive ZDF rat between 8.5-10-weeks of age and persisted up until 25-weeks old or longer. The ZDF rat 5-HT2A receptor-targeting autoantibodies caused acute neurite retraction and accelerated mouse neuroblastoma cell loss by a mechanism involving activation of Gq11/PLC/IP3R pathway and RhoA/Rho kinase coupled signaling. The ZDF and lean heterozygous Zucker rat strains may be suitable animal models for investigations of the roles of obesity-associated 
inflammation and dysregulated humoral immunity, respectively, in the etiology of certain forms of late-onset neurodegeneration.

\section{Funding}

This project was supported by grants from the New Jersey Commission on Brain Injury Research (CBIR19PIL007) to MBZ and the Biomedical Laboratory Research and Development Service of the VA Office of Research and Development (I1BX004561) to KCHP. The views expressed in this article are those of the authors and do not necessarily reflect the position or policy of the Department of Veterans Affairs or the United States government.

\section{References}

1. Hu G, Pekka J, Siamak B, Riitta A, Jaakko T (2007) Type 2 Diabetes and the Risk of Parkinson's Disease. Diabetes Care 30(4): 842-847. [crossref]

2. Xu WL, Qiu CX, Wahlin A, Winblad B, Fratiglioni L (2004) Diabetes mellitus and risk of dementia in the Kungsholmen project: a 6-year follow-up study. Neurology 63(7): 1181-1186. [crossref]

3. Prieto GA, Tong L, Smith ED, Cotman CW (2019) TNFa and IL-1 $\beta$ but not IL18 Suppresses Hippocampal Long-Term Potentiation Directly at the Synapse. Neurochem Res 44(1): 49-60. [crossref]

4. Qin XY, Zhang SP, Cao C, Loh YP, Cheng Y (2016) Aberrations in Peripheral Inflammatory Cytokine Levels in Parkinson Disease: A Systematic Review and Metaanalysis. JAMA Neurol 73(11): 1316-1324. [crossref]

5. Baumann H, Morella KK, White DW, Dembski M, Bailon PS, Kim H, Lai CF, Tartaglia LA (1996) The full-length leptin receptor has signaling capabilities of interleukin 6-type cytokine receptors. Proc Natl Acad Sci U S A 93(16): 8374-8. [crossref]

6. Dozio E, Ruscica M, Galliera E, Corsi MM, Magni P (2009) Leptin, ciliary neurotrophic factor, leukemia inhibitory factor and interleukin-6: class-I cytokines involved in the neuroendocrine regulation of the reproductive function. Curr Protein Pept Sci 10(6): 577- 584. [crossref]

7. Lord, G., Matarese, G., Howard, J. et al. (1998) Leptin modulates the T-cell immune response and reverses starvation-induced immunosuppression. Nature 394, 897-901. [crossref]

8. Clark JB, Palmer CJ, Shaw WN (1983) The diabetic Zucker fatty rat. Proc Soc Exp Biol Med 173(1): 68-75. [crossref]

9. Kurtz TW, Morris RC, Pershadsingh HA (1989) The Zucker fatty rat as a genetic model of obesity and hypertension. Hypertension 13: 896-901. [crossref]

10. Shibata T, Takeuchi S, Yokota S, Kakimoto K, Yonemori F, Wakitani K (2000) Effects of peroxisome proliferator-activated receptor-alpha and -gamma agonist, JTT-501, on diabetic complications in Zucker diabetic fatty rats. Br J Pharmacol 130(3): 495504. [crossref]

11. Ruth MR, Taylor CG, Zahradka P, Field CJ (2008) Abnormal immune responses in $\mathrm{fa} / \mathrm{fa}$ Zucker rats and effects of feeding conjugated linoleic acid. Obesity Silver Spring 16(8): 1770-9. [crossref]
12. Tanaka SI, Isoda F., Yamakawa T., Ishihara M, Sekihara H (1998) T lymphopenia in genetically obese rats. Clinical Immunology and Immunopathology 86(2): 219-225. [crossref]

13. Imai T, Cho YM, Takahashi M, Kitahashi T, Takami S, Nishikawa A, Ogawa K (2013) High susceptibility of heterozygous (+/fa) lean Zucker rats to 7,12-dimethylbenz(a) anthracene-induced mammary carcinogenesis. Oncol Rep 29(5): 1914-1922. [crossref]

14. Lourenço EV, Liu A, Matarese G, La Cava A (2016) Leptin promotes systemic lupus erythematosus by increasing autoantibody production and inhibiting immune regulation. Proc Natl Acad Sci U S A 13(38): 10637-10642. [crossref]

15. Zimering MB (2019) Autoantibodies in Type-2 Diabetes having Neurovascular Complications Bind to the Second Extracellular Loop of the 5-Hydroxytryptamine 2A Receptor. Endocrinol Diabetes Metab J 3(4): 1-8. [crossref]

16. Zimering MB (2017) Diabetes Autoantibodies Mediate Neural- and Endothelial CellInhibitory Effects Via 5-Hydroxytryptamine- 2 Receptor Coupled to Phospholipase C/Inositol Triphosphate/Ca2+ Pathway. I Endocrinol Diabetes 4(4): 10.15226/23746890/4/4/00184. [crossref]

17. Xu T, Pandey SC (2000) Cellular localization of serotonin (2A) (5HT (2A)) receptors in the rat brain. Brain Res Bull 51: 499-505. [crossref]

18. Alsip NL, Harris PD, Durrani GE (1991) Multiple Serotonin Receptors on Large Arterioles in Striated Muscle. J Vasc Res 28: 537-541. [crossref]

19. Zimering MB, Patel D, Bahn G (2019) Type 2 Diabetes Predicts Increased Risk of Neurodegenerative Complications in Veterans Suffering Traumatic Brain Injury. $J$ Endocrinol Diabetes 6(3). [crossref]

20. Schmid CL, Raehal KM, Bohn LM (2008) Agonist-directed signaling of the serotonin 2A receptor depends on beta-arrestin-2 interactions in vivo. Proc Natl Acad Sci U S A 105: 1079-1084. [crossref]

21. Zimering MB, Nadkarni SG (2019) Schizophrenia Plasma Autoantibodies Promote 'Biased Agonism' at the 5-Hydroxytryptamine 2A Receptor: Neurotoxicity is Positively Modulated by Metabotropic Glutamate 2/3 Receptor Agonism. Endocrinol Diabetes Metab J 3. [crossref]

22. Zimering MB, Anderson RJ, Moritz TE, Ge L (2009) Investigators for the VADT Endothelial cell inhibitory autoantibodies are associated with laser photocoagulation in adults from the Veterans Affairs Diabetes Trial. Metabolism 58(6): 882-7. [crossref]

23. Han J, Woytowich AE, Mandal AK, Hiebert LM (2007) Heparanase upregulation in high glucose-treated endothelial cells is prevented by insulin and heparin. Exp Biol Med (Maywood) 232(7): 927-34. [crossref]

24. Chen G, Wang D, Vikramadithyan R, Yagyu H, Saxena U, Pillarisetti S, Goldberg IJ (2004) Inflammatory cytokines and fatty acids regulate endothelial cell heparanase expression. Biochemistry 43(17): 4971-7. [crossref]

25. Faaber P, Rijke TP, van de Putte LB, Capel PJ, Berden JH (1986) Cross-reactivity of human and murine anti-DNA antibodies with heparan sulfate. The major glycosaminoglycan in glomerular basement membranes. J Clin Invest 77(6): 1824-30. [crossref]

26. M.B. Zimering, A.T. Pulikeyil, CE Myers, KC Pang (2020) Serotonin 2A Receptor Autoantibodies Increase in Adult Traumatic Brain Injury In Association with Neurodegeneration. J Endocrinol Diab 7(1): 1-8. [crossref]

\section{Citation:}

Zimering MB, Grinberg M, Burton J and Pang KCH (2020) Circulating Agonist Autoantibody to 5-Hydroxytryptamine 2A Receptor in Lean and Diabetic Fatty Zucker Rat Strains. Endocrinol Diabetes Metab J Volume 4(3): 1-7. 